\title{
Study on Relationship Between the Nutritional Status and Dental Caries in 8-12 Year Old Children of Udaipur City, India
}

\author{
Panwar NK, ${ }^{1}$ Mohan $A,{ }^{2}$ Arora $R,{ }^{3}$ Gupta $A,{ }^{1}$ Marya $\mathrm{CM},{ }^{4}$ Dhingra $\mathrm{S}^{5}$
}

${ }^{1}$ Department of Pedodontics and Preventive Dentistry

IDST Dental College and hospital

Ghaziabad Uttar Pradesh

${ }^{2}$ Department of Physiology

MAMC Medical College, New Delhi

${ }^{3}$ Department of Pedodontics and Preventive Dentistry

Darshan Dental College and hospital

Udaipur, Rajasthan

Department of Public Health Dentistry

${ }^{4}$ Sudha Rustagi College of Dental sciences and Research

Faridabad Haryana

${ }^{5}$ SGT Dental College, Hospital and Research Institute Gurgaon, Haryana

Corresponding Author

Charu Mohan Marya

Department of Public Health Dentistry

Sudha Rustagi College of Dental sciences and Research

Haryana, India

Email: maryacm@yahoo.co.uk

\section{Citation}

Panwar NK, Mohan A, Arora R, Gupta A, Marya $\mathrm{CM}$, Dhingra $\mathrm{S}$. Study on Relationship Between the Nutritional Status and Dental Caries in 8-12 Year Old Children of Udaipur City, India. Kathmandu Univ Med J 2014;45(1):26-31.

\section{ABSTRACT}

\section{Background}

The future health of individuals depends on the well being of the children of today. Proper nutrition for children is very important. The most commonly used index of obesity and over weight is Body Mass Index. The growth of children should be monitored using the Body Mass Index (BMI) and risk factors assessed through a dietary and physical activity history. The increase in obesity is attributed to increased carbohydrate consumption among children. Obesity and caries are both diet-based conditions that share a cause that is, excessive ingestion of fermentable carbohydrates.

\section{Objective}

This study was undertaken to determine the association of nutritional status with dental caries in 8 to 12 year old children of Udaipur city.

\section{Method}

The present study was conducted on a random sample of 1000 boys and girls, aged 8-12 years. The children were selected from schools located in the Udaipur City, Rajasthan. The schools examined were of government and private sector schools in Udaipur city. The children from schools of Udaipur city was taken in the study with male, female and age group ratio as per distribution in population. A proforma was used to record children's age, gender, school, year, height, weight, parental income and dental caries status. Statistical analysis was done using Statistical Package of Social Science (SPSS Version 15; Chicago Inc., USA).

\section{Result}

It was found that caries free individuals were more from normal nutritional status group with 134 (13.4\%) subjects where as only 11 (1.1\%) of subjects obese children were found caries free.

\section{Conclusion}

Study shows that the children with normal BMI for age had more caries in their primary teeth, as well as in their permanent teeth, than the overweight children.

\section{KEY WORDS}

Body Mass Index, dental caries, nutritional status 


\section{INTRODUCTION}

The future health of individuals' depends on the well being of the children of today. Proper nutrition for children is very important. Both the quality and quantity of food choice have the potential to enhance or interfere with normal growth and development. Malnutrition is one of the most common cause or contributing factor to illness and is the basic cause of suboptimal physical and mental development. It is the most important endogenous factor contributing to the restricted development of a nation. ${ }^{1}$ The most commonly used index of obesity and over weight is BMI. ${ }^{2}$ Oral health is also strongly influenced by the intake of sugar-rich foods and high dental decay scores are associated with unbalanced dietary patterns. ${ }^{3}$ Dental caries during childhood continues to be a significant public health concern. ${ }^{4} \mathrm{He}$ also gave the causative relation between refined carbohydrates and dental caries and also link between dietary intake and increase in overweight. It is appropriate to hypothesize that being overweight might also be a marker for dental caries in children and teenagers. In this study, a wide age group from 8-12 years was selected because as individuals grow, their dietary needs and habits also change and also the amount of body fat changes with age which represent a dynamic phase in the growth and development of the child. Similarly both boys and girls were considered to take into account the gender differences in the amount of body fat due to differences in the growth milestones, body structure and hormonal effects. This study was thus undertaken to determine the relationship between nutritional status and dental caries in children of Udaipur city. The future health of individuals' depends on the well being of the children of today. Proper nutrition for children is very important. Both the quality and quantity of food choice have the potential to enhance or interfere with normal growth and development. Malnutrition is one of the most common cause or contributing factor to illness and is the basic cause of suboptimal physical and mental development. It is the most important endogenous factor contributing to the restricted development of a nation. ${ }^{1}$ The most commonly used index of obesity and over weight is $\mathrm{BMI}^{2}$ Oral health is also strongly influenced by the intake of sugar-rich foods and high dental decay scores are associated with unbalanced dietary patterns. ${ }^{3}$ Dental caries during childhood continues to be a significant public health concern. ${ }^{4} \mathrm{He}$ also gave the causative relation between refined carbohydrates and dental caries and also link between dietary intake and increase in overweight. It is appropriate to hypothesize that being overweight might also be a marker for dental caries in children and teenagers. In this study, a wide age group from 8-12 years was selected because as individuals grow, their dietary needs and habits also change and also the amount of body fat changes with age which represent a dynamic phase in the growth and development of the child. Similarly both boys and girls were considered to take into account the gender differences in the amount of body fat due to differences in the growth milestones, body structure and hormonal effects. This study was thus undertaken to determine the relationship between nutritional status and dental caries in children of Udaipur city.

\section{METHODS}

A descriptive cross sectional study was conducted to assess the nutritional status and dental caries among $8-12$ years old school going children in Udaipur city, Rajasthan. The schools examined were of government and private sector schools in Udaipur city. This study was reviewed by the institutional ethical committee of Darshan Dental College and Hospital and clearance was obtained. Institutional consent was taken from the Head of the institute, as the subjects were not in a position to understand the consent form. To ensure uniform interpretation, understanding and application by the examiner, of the codes and criteria for the various diseases and conditions to be observed and recorded in the proforma used, the examiner was priorly calibrated and trained in the Department.

\section{Inclusion criteria}

- 1000 children from schools of Udaipur city was taken in the study with male and female and age group ratio as per distribution in population.

- Children belonging to 8 to 12 years age group was selected to evaluate the extent of caries in mixed dentition stage

\section{Exclusion criteria}

- Children with dentofacial deformities or any syndrome were excluded.

- Uncooperative, medically and physically compromised patients were excluded.

- Children on long term medication.

- Children undergoing orthodontic treatment.

A proforma was used to record children's age, gender, school, year, height, weight, parental income and dental caries status. Dental caries was recorded according to WHO criteria. The examiner visited the residential institutes on the predetermined dates as according to the schedule with a trained recorder, where the recorder recorded the general information and the clinical examination finding as dictated by the examiner. Clinical examinations were carried out at the institute's medical room or classroom with the aid of a mouth mirror, explorer and under adequate natural light and proforma was duly filled.

\section{Nutritional status}

In order to obtain BMI-for-age, given by Ancel Keys in 1972, height and weight of each child was recorded. The weight of each child without shoes was measured to the nearest $0.5 \mathrm{~kg}$, using a portable analog weighing machine (ModelLibra, Mfd. By - Edryl-India Itd. lihas, Goa). The height was measured to the nearest $0.5 \mathrm{~cm}$, using portable height 
measuring unit (floor model, upto two meters height, mfd. By Narang scales Enterprises, Agra).

Body Mass Index (BMI) was calculated using the following formula i.e. weight in kilograms divided by height in meter square (weight/height 2).

\section{$\mathrm{BMI}=\underline{\text { Weight }(\mathrm{kg})}$}

Height2 (m2)

The total obtained was classified according to the International Classification of underweight, overweight and obesity according to BMI given by WHO. (Table 1)

Table 1. The International Classification of underweight, overweight and obesity according to BMI.

\begin{tabular}{|cc|}
\hline Classification & Principal cut-off points \\
\hline Underweight & $<18.50$ \\
\hline Normal range & $18.50-24.99$ \\
\hline Overweight & $\geq 25.00$ \\
Obese & $\geq 30.00$ \\
\hline
\end{tabular}

Source: Adapted from WHO 1995, WHO 2000 and WHO 2004. ${ }^{5}$

The data obtained was subjected to statistical analysis with the consult of a statistician. Statistical analysis was done using Statistical Package of Social Science (SPSS Version 15; Chicago Inc., USA). The tests employed were Chi-Square $\left(X^{2}\right)$ Test and Analysis of Variance (ANOVA), Significance level was fixed at $P<0.05$

\section{RESULTS}

It was found in the study that among 1000 children aged between 8 to 12 years, 500 (50\%) were males and 500 $(50 \%)$ were females. Maximum subjects were of nine years old age group (20.7 \%) (Table 2 ). Two hundred ninety two

Table 2. Distribution of study group according to age and gender.

\begin{tabular}{|ccccccc|}
\hline $\begin{array}{c}\text { Age } \\
\text { (Years) }\end{array}$ & \multicolumn{2}{c}{ Males } & \multicolumn{2}{c}{ Females } & \multicolumn{2}{c|}{ Total } \\
\hline 8 & $\mathbf{N}$ & $\%$ & $\mathbf{N}$ & $\%$ & $\mathbf{N}$ & $\%$ \\
\hline 9 & 121 & 12.1 & 86 & 8.6 & 207 & 20.7 \\
\hline 10 & 119 & 11.9 & 86 & 8.6 & 204 & 20.4 \\
\hline 11 & 93 & 9.3 & 104 & 10.4 & 197 & 19.7 \\
\hline 12 & 84 & 8.4 & 104 & 10.4 & 197 & 19.7 \\
\hline Total & 500 & 50.0 & 500 & 50.0 & 1000 & 100 \\
\hline
\end{tabular}

Chi-square value: 4.11 , p-Value: 0.39

were found underweight and 137 (13.7\%) were males and 155 (15.5\%) were females. There were 474 (47.4\%) children of normal BMI-for-age, of which 260 (26.0\%) were males and 214 (21.4\%) were females. Out of 184 (18.4\%) risks of overweight children, there were $86(8.6 \%)$ males and 98 (9.8\%) females. The 227 (22.7\%) overweight children comprised of $17(1.7 \%)$ males and $33(3.3 \%)$ females (Table 3). The distribution of caries prevalence in primary dentition
Table 3. Distribution of study group according to BMI for age and gender.

\begin{tabular}{|ccccccc|}
\hline BMI for Age & \multicolumn{2}{c}{ Males } & \multicolumn{2}{c}{ Females } & \multicolumn{2}{c|}{ Total } \\
& N & $\%$ & N & $\%$ & N & $\%$ \\
\hline Underweight & 137 & 13.7 & 155 & 15.5 & 292 & 29.2 \\
\hline Normal & 260 & 26.0 & 214 & 21.4 & 474 & 47.4 \\
\hline Overweight & 86 & 8.6 & 98 & 9.8 & 184 & 18.4 \\
\hline Obese & 17 & 1.7 & 33 & 3.3 & 50 & 5.0 \\
\hline Total & 500 & 50.0 & 500 & 50.0 & 1000 & 100 \\
\hline
\end{tabular}

Chi-square value: 3.22 , p-value: 0.72

in various nutritional status groups revealed that caries free individuals were more, $111(11.1 \%)$ from underweight nutritional status group where as only 13 (1.3\%) Obese children were found caries free. While caries active subjects were mainly from normal nutritional status group with 393 (39.3\%) subjects followed by overweight subjects with 136 (13.6\%) children (Table 4). Mean level of caries prevalence with $\mathrm{dt}, \mathrm{mt}, \mathrm{ft}$, and deft with standard deviation according to age groups and gender clearly showed that the $\mathrm{dt}$ component was highest among 10 years old subjects with $2.29 \pm 1.68$, followed by nine years old children with 2.13 \pm 1.68 . Least affected age group was found to be 11 years age group with $1.39 \pm 1.21$. dt forms the major component of deft with $1.81 \pm 1.40$ followed by $\mathrm{ft}$ with $0.06 \pm 0.35$. The results showed higher degree of significance value 0.000 ; Table 5). The mean level of caries prevalence with DT, MT, FT, and DMFT with standard deviation according to age groups and gender clearly showed that the DT component was highest among 10 years old subjects with $1.94 \pm 1.66$, followed by 9 years old children with $1.75 \pm 1.58$. Least affected age group was found to be 11 years age group with $1.29 \pm 1.56$.DT forms the major component of DMFT with $1.61 \pm 1.48$ followed by FT with $0.07 \pm 0.44$. The results showed higher degree of significance value (Table 6$)$. The distribution of caries prevalence in permanent dentition in various nutritional status groups revealed that caries

Table 4. Prevalence of dental caries in primary dentition in study population according to $\mathrm{BMI}$ for age.

\begin{tabular}{lcccc}
\hline BMI for age & & $\begin{array}{c}\text { Caries } \\
\text { free }\end{array}$ & $\begin{array}{c}\text { Caries } \\
\text { active }\end{array}$ & Total \\
\hline Underweight & $\mathrm{N}$ & 111 & 181 & 292 \\
\hline Normal & $\%$ & $11.1 \%$ & $18.1 \%$ & $29.2 \%$ \\
\hline & $\mathrm{N}$ & 81 & 393 & 474 \\
\hline Overweight & $\%$ & $8.1 \%$ & $39.9 \%$ & $47.7 \%$ \\
\hline Obese & $\mathrm{N}$ & 48 & 136 & 184 \\
& $\%$ & $4.8 \%$ & $13.6 \%$ & $18.4 \%$ \\
\hline Total & $\mathrm{N}$ & 13 & 37 & 50 \\
& $\%$ & $1.3 \%$ & $3.7 \%$ & $5.0 \%$ \\
\hline & $\mathrm{N}$ & 253 & 747 & 1000 \\
\hline
\end{tabular}

Chi square value: $41.958, \mathrm{p}$ value -0.000 
Table 5. Mean deft score according to age groups among male and female subjects.

\begin{tabular}{|c|c|c|c|c|c|c|c|c|c|}
\hline \multirow[t]{3}{*}{ Age } & \multirow[t]{3}{*}{ Sex } & \multicolumn{8}{|c|}{ Deft Scores } \\
\hline & & \multicolumn{2}{|l|}{ Dt } & \multicolumn{2}{|l|}{ Et } & \multicolumn{2}{|l|}{$\mathrm{Ft}$} & \multicolumn{2}{|l|}{ Deft } \\
\hline & & Mean & SD & Mean & SD & Mean & SD & Mean & SD \\
\hline \multirow[t]{3}{*}{8} & Male & 1.77 & 1.15 & 0.00 & 0.00 & 0.10 & 0.50 & 1.87 & 1.11 \\
\hline & Female & 1.73 & 0.99 & 0.00 & 0.00 & 0.09 & 0.43 & 1.82 & 0.93 \\
\hline & & 1.75 & 1.07 & 0.00 & 0.00 & 0.09 & 0.47 & 1.85 & 1.02 \\
\hline \multirow[t]{3}{*}{9} & Male & 2.31 & 1.54 & 0.00 & 0.00 & 0.07 & 0.40 & 2.38 & 1.50 \\
\hline & Female & 1.93 & 1.40 & 0.01 & 0.01 & 0.07 & 0.43 & 2.01 & 1.41 \\
\hline & & 2.13 & 1.49 & 0.00 & 0.07 & 0.07 & 0.42 & 2.20 & 1.46 \\
\hline \multirow[t]{3}{*}{10} & Male & 2.71 & 1.65 & 0.00 & 0.00 & 0.05 & 0.37 & 2.76 & 1.60 \\
\hline & Female & 1.95 & 1.63 & 0.02 & 0.13 & 0.08 & 0.45 & 2.05 & 1.64 \\
\hline & & 2.29 & 1.68 & 0.01 & 0.10 & 0.07 & 0.42 & 2.37 & 1.66 \\
\hline \multirow[t]{3}{*}{11} & Male & 1.34 & 1.21 & 0.02 & 0.14 & 0.02 & 0.14 & 1.38 & 1.19 \\
\hline & Female & 1.45 & 1.22 & 0.03 & 0.23 & 0.02 & 0.21 & 1.50 & 1.18 \\
\hline & & 1.39 & 1.21 & 0.03 & 0.19 & 0.02 & 0.17 & 1.44 & 1.18 \\
\hline \multirow[t]{3}{*}{12} & Male & 1.40 & 1.20 & 0.10 & 0.39 & 0.03 & 0.18 & 1.53 & 1.15 \\
\hline & Female & 1.46 & 1.19 & 0.06 & 0.33 & 0.01 & 0.10 & 1.52 & 1.19 \\
\hline & & 1.43 & 1.19 & 0.08 & 0.36 & 0.02 & 0.14 & 1.53 & 1.17 \\
\hline Total & & 1.81 & 1.40 & 0.02 & 0.19 & 0.06 & 0.35 & 1.88 & 1.37 \\
\hline $\mathrm{F}$ value & & \multicolumn{2}{|c|}{90.94} & \multicolumn{2}{|c|}{3.90} & \multicolumn{2}{|c|}{3.173} & \multicolumn{2}{|r|}{14.98} \\
\hline$P$ value & & \multicolumn{2}{|c|}{0.000} & \multicolumn{2}{|c|}{0.000} & \multicolumn{2}{|c|}{0.001} & \multicolumn{2}{|r|}{0.000} \\
\hline
\end{tabular}

Table 6. Mean DMFT score according to age groups among male and female subjects.

\begin{tabular}{|c|c|c|c|c|c|c|c|c|c|}
\hline \multirow[t]{3}{*}{ Age } & \multirow[t]{3}{*}{ Sex } & \multicolumn{8}{|c|}{ DMFT Scores } \\
\hline & & \multicolumn{2}{|l|}{ DT } & \multicolumn{2}{|l|}{ MT } & \multicolumn{2}{|l|}{ FT } & \multicolumn{2}{|l|}{ DMFT } \\
\hline & & Mean & SD & Mean & SD & Mean & SD & Mean & SD \\
\hline \multirow[t]{3}{*}{8} & Male & 1.57 & 1.15 & 0.00 & 0.00 & 0.07 & 0.35 & 1.65 & 1.12 \\
\hline & Female & 1.37 & 1.05 & 0.02 & 0.21 & 0.11 & 0.48 & 1.52 & 1.08 \\
\hline & & 1.47 & 1.10 & 0.01 & 0.14 & 0.09 & 1.58 & 1.85 & 1.10 \\
\hline \multirow[t]{3}{*}{9} & Male & 1.96 & 1.58 & 0.02 & 0.19 & 0.04 & 0.27 & 2.03 & 1.59 \\
\hline & Female & 1.52 & 1.55 & 0.00 & 0.00 & 0.13 & 0.65 & 1.65 & 1.56 \\
\hline & & 1.75 & 1.58 & 0.01 & 0.14 & 0.08 & 0.49 & 1.85 & 1.58 \\
\hline \multirow[t]{3}{*}{10} & Male & 2.31 & 1.65 & 0.01 & 0.10 & 0.09 & 0.48 & 2.46 & 1.62 \\
\hline & Female & 1.63 & 1.61 & 0.01 & 0.09 & 0.17 & 0.75 & 1.84 & 1.65 \\
\hline & & 1.94 & 1.66 & 0.01 & 0.10 & 0.13 & 0.64 & 2.10 & 1.66 \\
\hline \multirow[t]{3}{*}{11} & Male & 1.20 & 1.50 & 0.01 & 0.10 & 0.03 & 0.22 & 1.24 & 1.49 \\
\hline & Female & 1.39 & 1.50 & 0.00 & 0.00 & 0.01 & 1.10 & 1.42 & 1.49 \\
\hline & & 1.29 & 1.50 & 0.01 & 0.07 & 0.02 & 0.17 & 1.32 & 1.49 \\
\hline \multirow[t]{3}{*}{12} & Male & 1.49 & 1.26 & 0.04 & 0.25 & 0.02 & 0.21 & 1.55 & 1.27 \\
\hline & Female & 1.64 & 1.56 & 0.01 & 0.10 & 0.07 & 0.42 & 1.71 & 1.59 \\
\hline & & 1.57 & 1.43 & 0.03 & 0.19 & 0.05 & 0.34 & 1.64 & 1.45 \\
\hline Total & & 1.61 & 1.48 & 0.01 & 0.13 & 0.07 & 0.44 & 1.70 & 1.49 \\
\hline F value & & \multicolumn{2}{|c|}{25.57} & \multicolumn{2}{|c|}{1.63} & \multicolumn{2}{|c|}{4.06} & \multicolumn{2}{|c|}{39.62} \\
\hline$P$ value & & \multicolumn{2}{|c|}{0.000} & \multicolumn{2}{|c|}{0.09} & \multicolumn{2}{|c|}{0.000} & \multicolumn{2}{|c|}{0.000} \\
\hline
\end{tabular}


free individuals were more from normal nutritional status group with 134 (13.4\%) subjects where as only 11 (1.1\%) of subjects obese children were found caries free. While caries active subjects were mainly from normal group with $340(34.0 \%)$ subjects followed by underweight subjects with $182(18.2 \%)$ children where as only 39 (3.9\%) obese children were caries active (Table 7).

Table 7. Prevalence of Dental Caries in Permanent Dentition in study population according to BMI for age

\begin{tabular}{lcccc} 
BMI for age & \multicolumn{2}{c}{$\begin{array}{l}\text { Caries } \\
\text { free }\end{array}$} & $\begin{array}{l}\text { Caries } \\
\text { active }\end{array}$ & Total \\
\hline Underweight & $\mathrm{N}$ & 110 & 182 & 292 \\
\hline Normal & $\%$ & $11.0 \%$ & $18.2 \%$ & $29.2 \%$ \\
\hline \multirow{2}{*}{ Overweight } & $\mathrm{N}$ & 134 & 340 & 474 \\
\hline Obese & $\%$ & $13.4 \%$ & $34.0 \%$ & $47.4 \%$ \\
\hline Total & $\mathrm{N}$ & 64 & 120 & 184 \\
& $\%$ & $6.4 \%$ & $12.0 \%$ & $18.4 \%$ \\
\hline & $\mathrm{N}$ & 11 & 39 & 50 \\
\hline & $\%$ & $1.1 \%$ & $3.9 \%$ & $5.0 \%$ \\
\hline & $\mathrm{N}$ & 319 & 618 & 1000 \\
\hline
\end{tabular}

Chi square value: 10.312 , p value -0.016

\section{DISCUSSION}

In many Indian homes, traditional food preparations are being gradually replaced by -ready to eat' products like highly refined cereals and bakery products. This is particularly evident in cities where both parents are employed. Due to the lack of time, they are compelled to consume/rely on 'fast foods', most of which are rich in carbohydrates, the role of refined carbohydrates in the etiology of caries is well documented in literature. ${ }^{6}$ Dental caries during childhood continues to be a significant public health concern. ${ }^{7}$ Childhood obesity and dental decay are multifactorial in nature and both result from complex interactions among these factors. ${ }^{8}$ Both the hypotheses that is 'obesity increases the risk of caries' and 'caries increases risk of obesity' are particularly logical. Rather, it is more realistic that a common risk factor increasesthe likelihood of both diseases, which are observed in association of caries risk in high obese subjects.

In our study, the mean deft score was observed to be significantly higher in normal children. Also, caries in primary dentition was observed to be significantly higher in normal children. These findings might illustrate that the relationship between $\mathrm{BMI}$ and dental caries in children is far more complex than can be explained by their dietary consumption alone. Studies have suggested that caries of the primary dentition is associated with early childhood period with poor nutrition. Nutrients such as vitamins $A$ and $D$, calcium and phosphorus have an effect on the gross and microscopic morphology, chemical composition and tooth eruption patterns. ${ }^{9}$ These factors in turn determine the susceptibility of a tooth to dental caries. The oral health problems associated with nutritional deficiencies occur as a result of inadequate dietary intake of all food groups.

In present study Caries in permanent dentition was observed to be high in normal children. The mean DMFT scores did not increase in children with increase in BMIfor-age. This observation was in contrast with studies that reported high caries scores in children with a high BMI. ${ }^{10-16}$ On the contrary studies done on US children have shown that overweight children were less likely to have caries than normal weight children as a lot of emphasis given to proper health education and dietary counseling to the parents of these children. ${ }^{17,18}$

\section{CONCLUSION}

Our study shows that the children with normal BMI-forage had more caries in their primary teeth, as well as in their permanent teeth, than the overweight children. Both overweight and dental caries are diet and awareness based conditions wherein, children with excessive ingestion of fermentable carbohydrates have a higher prevalence of dental caries. The role of physical activity in body weight regulation remains ambiguous. It has been suggested that children who engage themselves mostly in sedentary activities may have different patterns of food consumption and snacking, there by affecting their BMI. Further investigation on the relationship between physical activity, $\mathrm{BMI}$ and caries can be carried out.

\section{REFERENCES}

1. Peña M, Bacallao J. Malnutrition and poverty. Annual Rev. Nutr 2002;22: 241-253.

2. Shumei S, William Cameron. Tracking of body mass index in children in relation to overweight in adulthood. American Journal of Clinical Nutrition. 1999; 70(1): 1-11.

3. Oliver RC, Holm Pederson P, Loe H. The correlation between clinical coring,exudates measurements and microscopic evaluation of inflammation in the gingival. Journal Of Periodontology. 1985;56:293296

4. Benjamin B.M, Russel A.L, Smiley R.D. Periodontal Disease in rural Children. J Periodont. 1957, $28: 286$

5. WHO. BMI Classification [Internet] 2004 [ updated 2014 June 09]. Available from : http://apps.who.int/bmi/index. jsp?introPage=intro_3.html.

6. Kopycka-Kedzierawski DT, Auinger P, Billings RJ. Caries status and overweight in 2-18 - year - old US children: findings from national surveys. Community Dent Oral Epidemiol. 2008; 36: 157-167

7. Matsson L,Goldberg P.Gingival inflammatory reaction in children at different ages. Journal Of Clinical Periodontology. 1985;12:98-103

8. Psoter WJ, Reid BC, Katz RV. Malnutrition and dental caries. A review of literature. Caries Res. 2005; 39: 441-447.

9. Bond JT, Filer U. Thomson AM. Infant and child feeding. NewYork; Academic press: 1981: 349-362.

10. Newsom KL, Fadavi S, Koeeber S. Relationship between obesity and caries ill children. American Association of Dental Research; Chicago Section:2007. 
11. Tilahun Adera. Is childhood obesity a risk factor for dental caries. A population based study. Public Health Times; Research Day: 2005.

12. Jamelli SR, Rodrigues CS, de Lira PI. Nutritional status and prevalence of dental caries among 12-year-old children at public schools: a casecontrol study. Oral Health Prev Dent. 2010;8(1):77-84.

13. Juthamas Lueangpainsamut, Supaporn Chatrchaiwiwatana, Warangkana Inthalohit. Dental Caries Status and Nutritional Status in Children. KDJ. 2011; 14(1): 63.

14. Chiu, S. H, Dimarco, M. A, Prokop, J. L. Childhood obesity and dental caries in homeless children. Journal of Pediatric Health Care. 2012.
15. Honne T, Pentapati K, Kumar N, Acharya S. Relationship between obesity/overweight status, sugar consumption and dental caries among adolescents in South India. Int J Dent Hyg. 2012 Nov;10(4):240244.

16. Madhumati Chatterjee, Arup Ratan Bandyopadhyay. A Study on Nutritional Status and Dental Caries in Permanent Teeth among School Going Girl of Bengalee Population, India. Advances in Anthropology. 2012; 2(3): 112-116.

17. Mark D, Mitola DJ. Exploring the association between overweight and dental caries among US children. Pediatric Dentistry. 2006; 28(4): $375-380$

18. James A, David E, Jennifer U. Community socioeconomic status and children's dental health. JADA. 2001; 132: 216-222. 